\title{
ECLIM-SEHOP, a new platform to set up and develop international academic clinical trials for childhood cancer and blood disorders in Spain
}

\author{
F. Bautista ${ }^{1}$ - A. Cañete ${ }^{2}$. G. L. Ramírez-Villar ${ }^{3}$. J. M. Fernández ${ }^{2}$. J. L. Fuster ${ }^{4}$. C. Diaz de Heredia ${ }^{5}$. I. Astigarraga ${ }^{6}$. \\ M. García-Ariza ${ }^{6} \cdot$ S. Rives ${ }^{7}$. J. L. Dapena ${ }^{7} \cdot$ C. Márquez $^{3} \cdot$ A. Molinés ${ }^{8} \cdot$ M. del M. Bermúdez ${ }^{4} \cdot$ S. Gallego ${ }^{5}$.

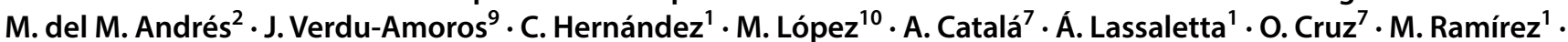 \\ F. Lendínez ${ }^{11} \cdot$ A. Carboné ${ }^{12} \cdot$ J. Gomez Sirvent ${ }^{13} \cdot$ M. Tallón $^{14} \cdot$ T. Acha $^{15} \cdot$ L. Moreno ${ }^{5}$ - A. Fernández-Teijeiro ${ }^{16}$ on \\ behalf of the Sociedad Española de Hematología y Oncología Pediátrica (SEHOP)
}

Received: 26 September 2019 / Accepted: 27 September 2019 / Published online: 9 October 2019

(c) The Author(s) 2019

\begin{abstract}
Introduction Cancer and blood disorders in children are rare. The progressive improvement in survival over the last decades largely relies on the development of international academic clinical trials that gather the sufficient number of patients globally to elaborate solid conclusions and drive changes in clinical practice. The participation of Spain into large international academic trials has traditionally lagged behind of other European countries, mainly due to the burden of administrative tasks to open new studies, lack of financial support and limited research infrastructure in our hospitals.

Methods The objective of ECLIM-SEHOP platform (Ensayos Clínicos Internacionales Multicéntricos-SEHOP) is to overcome these difficulties and position Spain among the European countries leading the advances in cancer and blood disorders, facilitate the access of our patients to novel diagnostic and therapeutic approaches and, most importantly, continue to improve survival and reducing long-term sequelae. ECLIM-SEHOP provides to the Spanish clinical investigators with the necessary infrastructural support to open and implement academic clinical trials and registries.

Results In less than 3 years from its inception, the platform has provided support to 20 clinical trials and 8 observational studies, including 8 trials and 4 observational studies where the platform performs all trial-related tasks (integral support: trial setup, monitoring, etc.) with more than 150 patients recruited since 2017 to these studies. In this manuscript, we provide baseline metrics for academic clinical trial performance that permit future comparisons.

Conclusions ECLIM-SEHOP facilitates Spanish children and adolescents diagnosed with cancer and blood disorders to access state-of-the-art diagnostic and therapeutic strategies.
\end{abstract}

Keywords Pediatric hematology and oncology $\cdot$ Clinical trials $\cdot$ Drug development $\cdot$ Clinical research

\section{Introduction}

\section{Childhood cancer}

L. Moreno and A. Fernández-Teijeiro are both the co-senior authors.

Electronic supplementary material The online version of this article (https://doi.org/10.1007/s12094-019-02221-9) contains supplementary material, which is available to authorized users.

L. Moreno

lucas.moreno@vhebron.net

Extended author information available on the last page of the article
In Spain, a new case of cancer is diagnosed annually for every 6500 children under 15 years of age. This represents 1100 new cases between 0 and 14 years and 450 between 15 and 19 [1], only a small fraction of the nearly quarter of million new invasive cancer diagnosed in our country every year for the whole population if we include adults and the elderly [2]. Cancer represents the first cause of death due to disease in children. Nonetheless, survival has considerably improved within the past 30 years and current overall survival in Spain 
is $80 \%$ at 5 years [3]. These survival figures are still lower than data available for other countries of Western Europe such as Germany or France ( $>85 \%$ at 5 years) [4]. Despite important reductions in mortality, childhood cancer survivors still face an unacceptable burden of long-term toxicities and sequelae [5].

\section{Role of the Spanish Society of Pediatric Hematology and Oncology (SEHOP)}

In Spain, the Registro Español de Tumores Infantiles (RETI) was created in 1979, a milestone in Spanish pediatric oncology that has collected data on more than 26,000 patients [1]. In 2008, the Sociedad Española de Oncología Pediátrica (SEOP) and the Sociedad Española de Hematología Pediátrica (SEHP) merged into SEHOP bringing together 250 members (mainly pediatricians, hematologists, pediatric surgeons and radiotherapists) from more than 40 centers distributed throughout the national geography. The aim of SEHOP (http://www.sehop.org) is, on one hand, to promote the development of pediatric hematology and oncology in Spain in its facets of prevention, best medical care, training, teaching and research; and, on the other hand, to ensure the right that every child and adolescent have to be assisted in institutions that have the necessary means and sufficiently qualified health personnel using therapeutic schemes that are nationally or internationally recognized [6].

\section{Role of clinical trials in pediatric oncology}

International collaboration and collaborative clinical trials are the main factors contributing to the major improvements in survival for many childhood cancers [7-9]. For children and adolescents with cancer, participation in international clinical trials has become the standard of care, improving and ensuring the quality of the treatment received, as well as greatly increasing the scientific value of the work at a global level [10]. As stated in the document European Standards of Care for Children with Cancer [6]: "All children with cancer should be treated according to the best available treatment protocols. There is general agreement that this is best provided within units that are active in clinical research and cancer registration processes. When available, children should be offered the opportunity to participate in relevant clinical trials that aim to improve the optimal treatment for all children".

\section{Pediatric international clinical trials in Spain: current situation}

Until recently, the participation of Spain into pediatric international clinical trials has lagged behind from that of European countries [11]. After the implementation of the European Clinical Trials Directive in 2001 (Directive 2001/20/EC) [12], the model to set up academic clinical trials in Europe was that an international sponsor, generally a university or academic research center, takes the central roles of a sponsor, and relies on a network of national coordinating centers (NCC), which act as national sponsors in each of the member states where the trial is open. These NCCs have to undertake a variety of trial-related tasks such as regulatory submissions, yearly reports to ethics and competent authorities, site selection and site initiation and often monitoring or pharmacovigilance activities. For the first 10 years after this implementation, the meager research infrastructure at our country posed significant challenges for Spanish institutions (either universities, hospitals, research foundations or research institutes) to take on this NCC role. However, over the past 5 years, several factors have contributed to the improvement of the participation of Spain into international clinical trials:

1. The transition from individual Spanish institutional efforts to open large international trials, to a central Spanish pediatric infrastructure for implementing and developing international clinical trials, first created in 2014 and named ARCAHI (Armonización en el tratamiento del cáncer infantil y las hemopatías en España), and from 2017 further developed into the ECLIM-SEHOP platform (Ensayos Clínicos Internacionales Multicéntricos-SEHOP).

2. The progressive incorporation of five large pediatric Spanish centers from 2010 onwards into the Innovative Therapies for Children with Cancer Consortium (ITTC) (http://www.itcc-consortium.org), a European network focused on early phase clinical trials of new drugs whose aim is to develop novel therapies for the treatment of pediatric and adolescent cancers in cooperation with regulatory bodies, pharmaceutical companies, parents and patients.

3. The close collaboration between SEHOP and other Spanish cancer research collaborative groups, such as the Grupo Español de Investigación en Sarcomas (GEIS, http://www.grupogeis.org), that has opened the door to pediatric cancer units to adhere to large international trials that might not been possible otherwise (e.g., Euroewing 2012, IS-GEIS-OS-02).

4. The changes in 2007 in the European legislation favoring the development of new anticancer agents in children by means of the pediatric investigational plan (PIP) requisite for pharmaceutical companies [13] and the implementation in Spain in 2015 of the updated clinical trial regulation (Real Decreto 1090/2015, 4th December) [14] that facilitates the administrative burden and reduces the costs for opening new academic studies, among other changes; 
5. The increasing active partnership of the SEHOP working groups with International Collaborative Groups trial such as SIOPEN, Euronet, SIOP-BTG, SIOPEL, I-BFM, EICNHL or the Histiocyte Society and the leadership of Spanish investigators in European networks [e.g., the LINES trial (NCT01728155) in neuroblastoma being the first international trial in pediatric oncology sponsored by a Spanish institution (IIS La Fe, Valencia)].

The objective of this manuscript is to report the setup of the new collaborative platform ECLIM-SEHOP, as well as establishing baseline metrics for academic clinical trial performance that permits future comparisons.

\section{Materials and methods}

This manuscript is focused on providing descriptive metrics of all the activities conducted by the ECLIM-SEHOP platform from 2017 to 2019. The ECLIM-SEHOP platform database was queried for this purpose. Date cutoff for analysis was 31st July 2019. Data reported includes the setup of the platform, a description of its standard operating procedures (SOPs), a description of the trial portfolio and a baseline summary of trial metrics. Trial metrics are listed on Table 1.

\section{Results}

\section{Setup of ECLIM-SEHOP}

Following on the initial work of the ARCAHI initiative and the clinical trials office of SEHOP, the ECLIM-SEHOP platform was started in 2017 and fully established from 2018 onwards. The initial setup phase comprised the establishment of the platform organigram, development of SOPs for defining the evaluation and selection criteria for the studies to support and defining the roles of the members of the platform (Supplementary Document 1), and lastly the review and approval of the structure and SOPs by the SEHOP Executive Board. To have the capacity and expertise to perform all trial-related tasks required by international sponsors, an agreement with a contract research organization (CRO) experienced in the conduct of academic clinical trials was sought (http://www.sofpr omed.com).

\section{Objectives of ECLIM-SEHOP}

The objectives of the platform are:

1. To establish the infrastructure to allow the participation of Spain into international academic collaborative clinical trials.

2. To increase the number of academic international clinical trials open in Spain.

3. To improve the setup (timelines) and conduct (quality control) of academic and international clinical trials open in Spain.

4. To undertake trial-related activities as required from the international sponsors and national investigators:

4.1 Regulatory submissions to Spanish competent authority (AEMPS) and research ethics committee (CEIm)

4.2 Contract management and site setup (Site monitoring, pharmacovigilance, management of biological samples, central review of imaging and pathology).

Table 1 ECLIM-SEHOP trial metrics

Trial portfolio integral support)

Trial opening timelines (for trials with integral support)
Number of clinical trials open for recruitment per year (total and with integral support)

Number of observational studies open for recruitment per year (total and with integral support)

Number of patient registries open for recruitment per year (total and with integral support)

Total number of ongoing clinical trials (total and with integral support)

Total number of ongoing observational studies (total and with integral support)

Total number of patient registries (total and with integral support)

Total number of new patients recruited per year in clinical trials, observational studies and patient registries

For each clinical trial, percentage of actual recruitment from planned recruitment

Time from EC/CA submission to EC/CA approval

Time from EC/CA approval to first site open

Time from EC/CA approval to $>50 \%$ of the sites open

Time from first site open to first patient recruited

Time from EC/CA submission to first patient recruited

Time from first international site open to first Spanish site open 


\section{Structure and functioning of ECLIM-SEHOP}

ECLIM-SEHOP is hierarchically structured (Fig. 1). For each new clinical trial proposal, a clinical investigator member of SEHOP completes a "new trial form" which is submitted to the platform providing a summary of the trial and details of the level of support required. The Scientific Directors, together with an independent reviewer member of SEHOP, and external reviewers when needed, evaluate the feasibility and scientific quality of the proposal and decide to accept/reject the participation of the platform in the proposal (Fig. 2). The platform prioritizes peer-reviewed academic international phase II-III clinical trials from world-wide recognized research groups that are addressed to children with prevalent hematological or oncological conditions and can be quickly and effectively translated into clinical practice
(Supplementary Document 2 lists all selection criteria and the applicant investigator requisites).

\section{Support for clinical trials}

The platform also provides support to investigators for regulatory advice, center selection, central review of imaging and, sample shipment and biomarker analyses when required.

\section{ECLIM-SEHOP clinical trial portfolio}

From January 2017, the platform has provided support to 20 academic clinical trials, 8 observational studies and patient registries, 1 imaging platform (https://imagi ng.sehopcloud.org) and 2 clinical databases. Of those, the

Fig. 1 ECLIM-SEHOP Organigram. CRO Clinical Research Organization

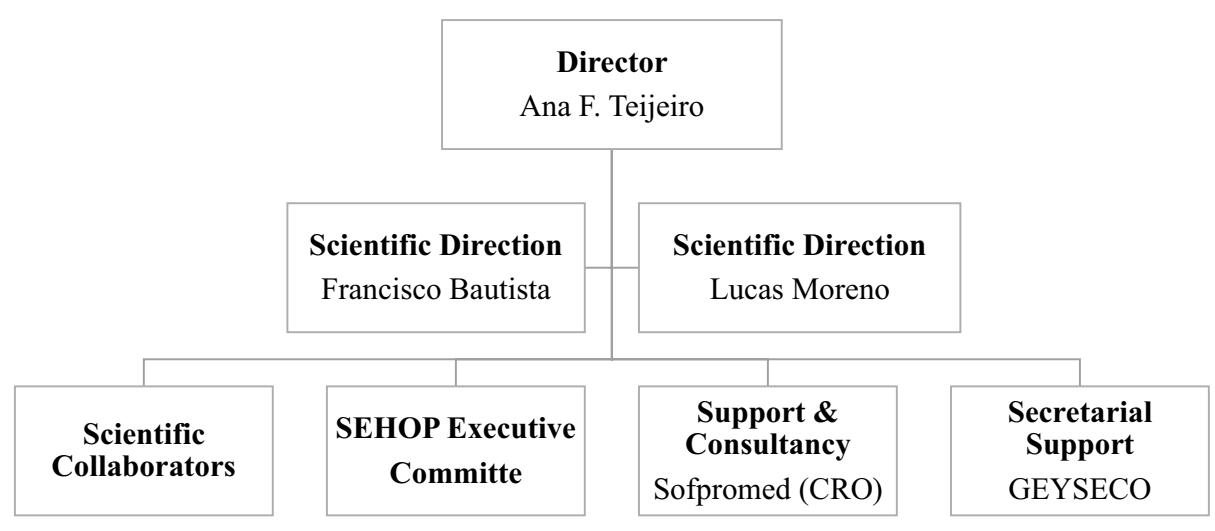

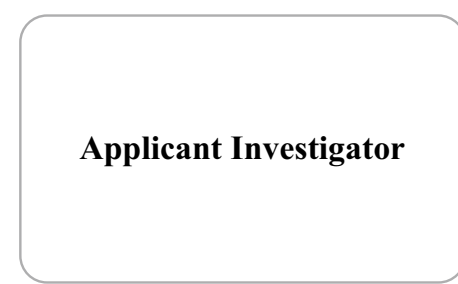
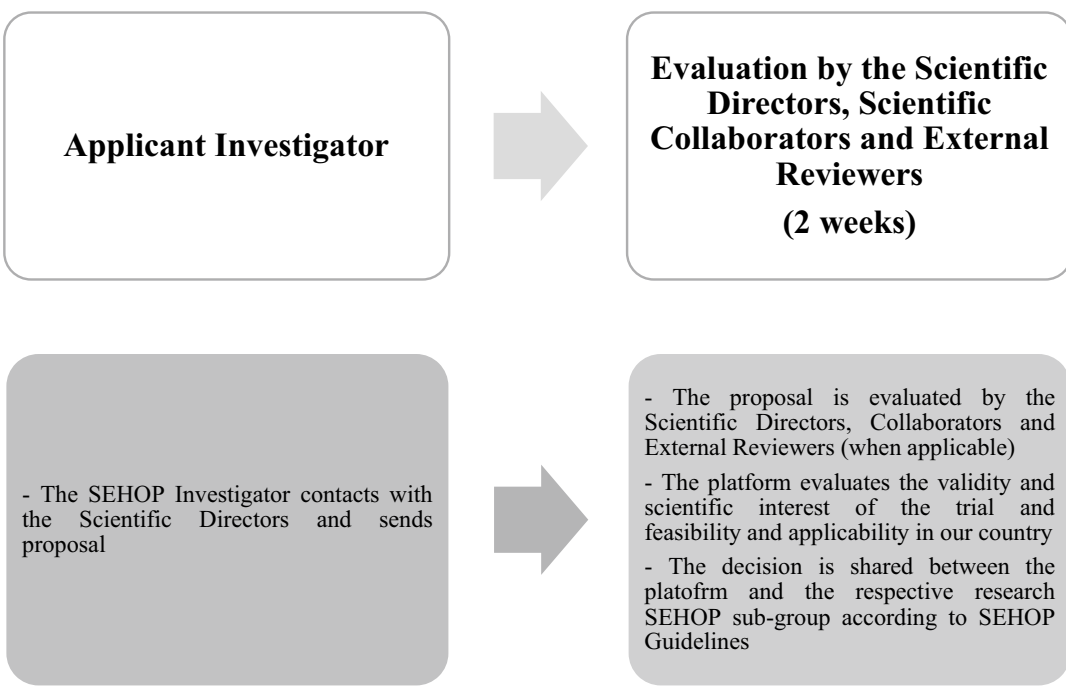

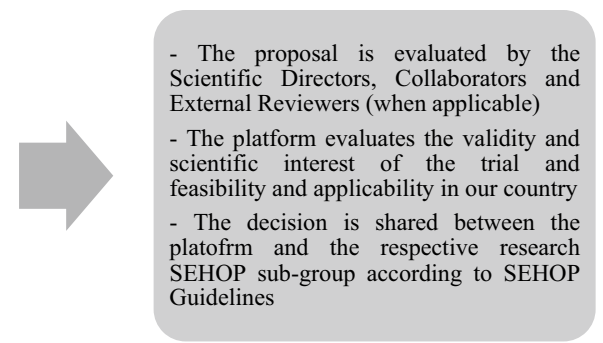

The platform communicates with the Investigator for the Decision of Go / No Go

Fig. 2 Decision chart of new clinical trials proposals for setup and implementation through the ECLIM-SEHOP platform. $C R O$ Clinical Research Organization 
platform provides integral support (e.g., all trial-related activities are conducted by the platform) for 8 clinical trials and 4 observational studies and patient registries (Fig. 3). These studies, which are internationally recognized as best standard of care in Europe, cover children and adolescents with leukemia (acute lymphoblastic leukemia [ALL], acute myeloid leukemia, infant ALL, bilineage acute leukemia, relapsed ALL), lymphoma (Hodgkin and non-Hodgkin lymphoma), Langerhans cell histiocytosis, brain tumors (ependymoma, medulloblastoma, diffuse intrinsic pontine glioma, low-grade glioma) and extracranial solid tumors (renal tumors, neuroblastoma, and soft tissue sarcomas). But also they focus on key transversal aspects such as allogeneic stem cell transplant, implementation of follow-up of late effects of childhood cancer (SIOPE survivors passport project; http://www.survivorsh ippassport.org). Fundación SEHOP is also covering the costs of clinical trial insurance for academic clinical trials conducted in Spain in pediatric cancer and blood disorders, including early clinical trials (phase 1 and 2) from national (CELYVIR [15]) or international academic initiatives such as MEMMAT [16] or the trials from the ITCC consortium (BIOMEDE ${ }^{\mathrm{NCT} 02233049}$, VINILO ${ }^{\mathrm{NCT} 01887522}$, BEACON [17], CRISP EUDRACT 2015-005437-53, ESMART NCT02813135) also supporting the opening of new therapeutic options for children with relapsed and refractory cancers in our country.

During 2019, new studies for soft tissue sarcomas, bone marrow failures and chronic neutropenias will also be adopted.

Integral support is provided to 8 clinical trials and 4 observational studies. This means that all national cosponsor activities are performed by the ECLIM-SEHOP platform, including trial setup, regulatory submissions and contracts or monitoring.

\section{Recruitment metrics}

In the five clinical trials with integral support that are open, 169 patients have been recruited from January 2017 onwards. Metrics for timelines for opening clinical trials are shown in Table 2.

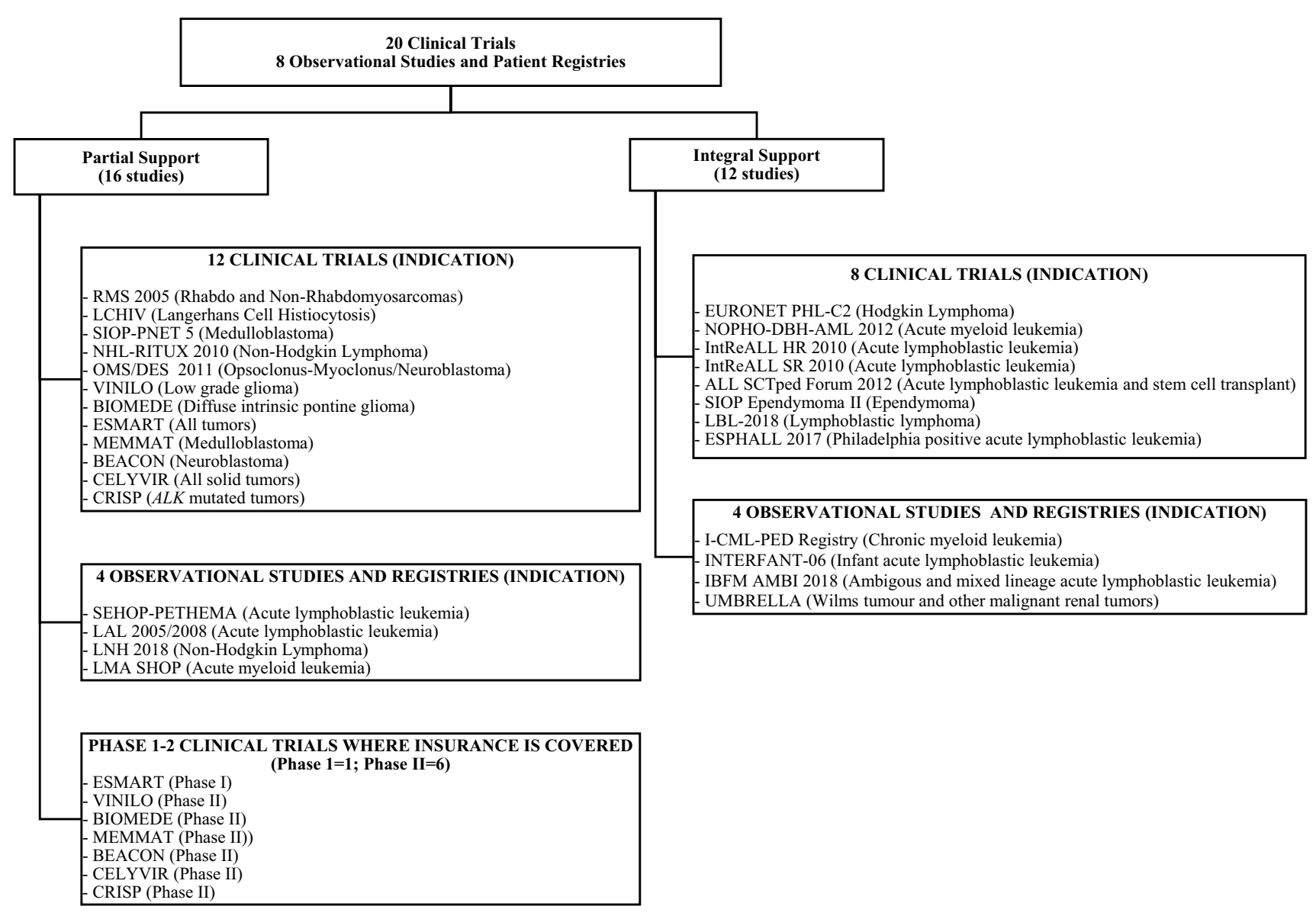

Fig. 3 ECLIM-SEHOP clinical trial and observational studies portfolio 
Table 2 ECLIM-SEHOP

recruitment metrics from all 8

clinical trials included (5 open, 3 in setup)

\begin{tabular}{lc}
\hline Metric & Median (range), in months \\
\hline Time from submission to CA approval (7 trials) & $3.0(0.6-8.6)$ \\
Time from CA approval to first site open (5 trials) & $9.1(1.2-38.5)$ \\
Time from CA approval to > 50\% of the sites open (4 trials) & $9.7(2.5-43.4)$ \\
Time from first site open to first patient recruited (4 trials) & $2.3(0.8-3.5)$ \\
Time from CA submission to first patient recruited (4 trials) & $11.4(8.7-49.9)$ \\
Time from first international site open to first Spanish site open (4 trials) & $41.5(14.7-62)$ \\
\hline
\end{tabular}

CA competent authorities

\section{Discussion}

Clinical trials are used to determine the most effective and safe treatments for a given disease. In childhood cancer, each trial aims at improving survival, reducing side effects or long-term sequelae of treatment. In some countries of Western Europe, participation in clinical trials has become the standard of care in children and adolescents with cancer.

To date, infrastructure and support to facilitate participation in academic international multicenter collaborative clinical trials in pediatric cancer in Spain has not matched the same standards than other European countries such as France, Germany or the United Kingdom. Initiatives like SCReN (Spanish Clinical Research Network, http://www. scren.es) provide excellent support to some clinical trials, but so far, have had limited resources and could not cover all the needs from the pediatric oncology community.

Historically, Spain has not been able to participate in multiple international clinical trials because of the abovementioned lack of resources and infrastructure to adapt to modern regulatory standards and provide good quality data. For some other studies, the time to setup the trials in our country has been so long due to administrative barriers that the trials were completed or nearly completed internationally by the time the trials were open.

The participation of our country in international clinical trials makes a huge contribution to our society for several reasons: (1) clinical trials evaluate more novel strategies and offer access to new treatments, (2) treatment within clinical trials is always done in centers with proven experience, with less variability and greater control of toxicities that may appear, being safer than being treated outside trials, (3) clinical trials allow to advance scientific knowledge and improve results of childhood cancer therapy and (4) collaboration at national and international level is essential to improve the results in such a significant group of rare diseases.

In our country, survival of childhood cancer has improved significantly in recent years, but the data are still below that of other neighboring countries in Western Europe such as France, the United Kingdom or Italy. For example, in the case of lymphoblastic leukemia, the EUROCARE5 study and a national study of the Registro Nacional de Tumores
Infantiles (RETI-SEHOP) have reported lower survival rates in Spain (83\%) compared to France (90\%), Germany (90\%), Italy $(89 \%)$ or United Kingdom $(88 \%)$ [4, 18].

With the implementation of the first European Clinical Trial Directive in 2001, the development and conduct of academic clinical trials entailed a significant burden of administrative duties at the international, national and local levels. These tasks surely exceed the capacity of individual clinical investigators in charge of each study as national coordinators. It was, therefore, necessary to provide support for all the new international clinical trials that are being implemented and maintain a stable and organized infrastructure to carry out these activities.

Since 2004, there has been a progressive improvement in our performance metrics as a country in clinical trial setup and conduct [19]. This positive change is due, among other factors, to changes in current legislation, learning curve of participating institutions and ethics committees.

Most of the activity in oncology clinical trials carried out in Spain is dependent on the pharmaceutical industry, which is surely more focused on new drug development, rather than on standard clinical practice, procedures such as transplant or surgery, radiotherapy or medical devices, and does not necessarily respond to the capabilities and opportunities of the clinical and academic research ecosystem, nor to the epidemiological reality of cancer in our country [20]. In Spain, $76 \%$ of this activity is industry sponsored, compared to that of $49 \%$ in France, $56 \%$ in the Netherlands, $62 \%$ in Italy or $65 \%$ in the United Kingdom. To improve our capacity to innovate in the field of clinical research, and achieve the goal that every child and adolescent in our country can potentially be included in a clinical trial, it is necessary for the Spanish public institutions to have greater funding and capabilities to develop more academic trials and implement collaborative international plans. ECLIM-SEHOP is supported with funds from competitive grants from the Asociación Española Contra el Cancer (AECC) and Fundación Inocente as well as other non-competitive contributions from non-profit organizations, mainly Federación Española de Padres de Niños con Cáncer, Asociación Pablo Ugarte y Fundación Mar, and, therefore, in constant need of identifying financial resources to make it sustainable. Still, our clinical trial setup metrics 
can be improved by far. Hopefully, the data provided here will serve as a baseline for future comparisons and, with time, the timelines to open clinical trial will shorten, so that these new advances reach our patients as soon as possible.

In summary, thanks to the enormous work and generosity of SEHOP members that are leading on these clinical trials and all stakeholders involved in this process, including parents, patients and other healthcare professionals, together with the help of the ECLIM-SEHOP platform we will facilitate Spanish children and adolescents diagnosed with cancer and blood disorders to access state-of-the-art diagnostic and therapeutic strategies, and in this way continue to improve survival rates and decreasing the side effects of long-term treatment.

Acknowledgements We would like to thank all children and parents who participate in clinical trials and the clinical staff, research nurses, and research assistants of the different institutions. We thank the members of the technical secretariat of the Sociedad Española de Hematología y Oncología Pediátrica (SEHOP) and Fundación SEHOP, particularly Inmaculada Toledano and Falastin Eljishi for their continued work, support and enthusiasm. We thank Patricio Ledesma, Head of Clinical Operations as well as all the staff at Sofpromed Investigación Clínica, for the close and fruitful collaboration in building up ECLIM-SEHOP. We are grateful to our colleagues of SEHOP and their teams (physicians, nurses, study coordinators, etc.) for their interest and commitment on clinical research to improve care for children with cancer and hematological diseases. We would specially like to thank Dr. Tomás Acha who, during his term as president of SEHOP, was the first to propose that a platform to support Spanish physicians and investigators was necessary to foster clinical research in pediatric cancer and blood disorders so that Spanish children had the same treatment opportunities as their peers in other European countries; he set up the foundations for the current ECLIM-SEHOP platform to be developed, together with the help of the SEHOP Executive Committee.

\section{Compliance with ethical standards}

Conflict of interest F Bautista had a consultant or advisory role for Bayer, Amgen and EusaPharma, received honoraria for speaking at symposia from Amgen and Jazz Pharmaceuticals and support for attending symposia from Takeda, EusaPharma, Shire and Jazz Pharmaceuticals. A. Cañete had a consultant or advisory role for Bayer and EusaPharma and received support for attending symposia from Nestle. A Cañete is a member of the Executive Committee of SIOPEN, nonprofit organization that receives royalties for the sales of dinutuximab beta. J. L. Fuster had a consultant or advisory role for Amgen, Jazz Pharmaceuticals and Novartis. He received honoraria for speaking at symposia from Amgen, Servier, Jazz Pharmaceuticals and Pfizer and support for attending symposia from Servier and Jazz Pharmaceuticals. I. Astigarraga had a consulting or advisory role for Novartis and Amgen. S. Rives had a consulting or advisory role for Novartis, Celgene, Amgen, JazzPharma, Shire and Servier. She received honoraria for educational events and travel expenses from Novartis, Celgene, JazzPharma, Shire and Amgen. She is member of the SSC Committee of the Novartis Clinical trial EudraCT Number: 2017-002116-14 and received honoraria from Novartis. J. Dapena had a consulting or advisory role for Novartis, Servier, Amgen, Jazz Pharmaceuticals, Shire and Sobi. A. Catalá had a consultant or advisory role for Novoinmune and received support for educational events and attending symposia from Novartis and Celgene. He is a beneficiary of a research grant from Instituto de Salud Carlos III. L. Moreno had a consulting or advisory role for Novartis, AstraZeneca, Roche Genentech, Bayer, Amgen, MundiPharma. He received honoraria from Celgene and Novartis for educational events and travel expenses from MundiPharma, Celgene, Amgen. L Moreno is a member of the Executive Committee of SIOPEN, non-profit organization that receives royalties for the sales of dinutuximab beta. A. Fernández-Teijeiro had a consulting or advisory role for Amgen, Novartis and Takeda. She received honoraria from Takeda and Amgen for educational events and travel expenses from Servier, Shire and Gilead. The rest of the authors declare that they have no conflict of interest.

Grant support ECLIM-SEHOP is supported by the grant "Cáncer infantil y cánceres poco frecuentes 2018" from Asociación Española Contra el Cáncer (AECC) (Grant CICPF18016FERN 2018), Fundación Inocente Inocente, Federación Española de Padres de Niños con Cáncer, Asociación Pablo Ugarte and Fundación MAR. Other academic clinical trials conducted in Spain are supported by many non-profit organizations to which we are also infinitely grateful as well as the SCReN platform.

Ethical standards All human studies had been approved by the appropriate ethics committee and had, therefore, been performed in accordance with the ethical standards laid down in the 1964 Declaration of Helsinki and its later amendments.

Informed consent Parents and/or legal guardians of children and adult patients participating in these clinical trials gave their informed consent prior to their inclusion in the studies reported in this manuscript.

Open Access This article is distributed under the terms of the Creative Commons Attribution 4.0 International License (http://creativeco mmons.org/licenses/by/4.0/), which permits unrestricted use, distribution, and reproduction in any medium, provided you give appropriate credit to the original author(s) and the source, provide a link to the Creative Commons license, and indicate if changes were made.

\section{References}

1. Peris-Bonet R. Incidencia y supervivencia del cáncer infantil. In: Madero L, Lassaleta A, Sevilla J, editors. Hematol y Oncol Pediátricas. 3rd ed. Madrid: Ergon; 2015. p. 263-70.

2. Galceran J, Ameijide A, Carulla M, Mateos A, Quirós JR, Rojas D, et al. Cancer incidence in Spain, 2015. Clin Transl Oncol. 2017;19:799-825.

3. Pardo E, Muñoz A, Valero S, Porta S, Barreda MS, Fernandez Delgado R, Peris R. Cáncer infantil en España. Estadísticas 19802018. Registro Español de Tumores Infantiles (RETI-SEHOP). Valencia: Universitat de Valencia; 2019.

4. Gatta G, Botta L, Rossi S, Aareleid T, Bielska-Lasota M, Clavel J, et al. Childhood cancer survival in Europe 1999-2007: results of EUROCARE-5-a population-based study. Lancet Oncol. 2014;15:35-47.

5. Armstrong GT, Chen Y, Yasui Y, Leisenring W, Gibson TM, Mertens AC, et al. Reduction in late mortality among 5-year survivors of childhood cancer. N Engl J Med. 2016;374:833-42.

6. European Standards of Care for Children with Cancer; 2009. https ://www.siope.eu/wp-content/uploads/2013/09/European_Stand ards_final_2011.pdf. Accessed 15 July 2019.

7. Kowalczyk JR, Samardakiewicz M, Pritchard-Jones K, Ladenstein R, Essiaf S, Fitzgerald E, et al. European Survey on Standards of Care in paediatric oncology centres. Eur J Cancer. 2016;61:11-9. 
8. Pritchard-Jones K, Sullivan R. Children with cancer: driving the global agenda. Lancet Oncol. 2013;14:189-91.

9. Zwaan CM, Kolb EA, Reinhardt D, Abrahamsson J, Adachi S, Aplenc R, et al. Collaborative efforts driving progress in pediatric acute myeloid leukemia. J Clin Oncol. 2015;33:2949-62.

10. Bonaventure A, Harewood R, Stiller CA, Gatta G, Clavel J, Stefan DC, et al. Worldwide comparison of survival from childhood leukaemia for 1995-2009, by subtype, age, and sex (CONCORD-2): a population-based study of individual data for 89828 children from 198 registries in 53 countries. Lancet Haematol. 2017;4:e202-17.

11. Bautista F, Gallego S, Cañete A, Mora J, Diaz de Heredia C, Cruz O, et al. Landscape of early clinical trials for childhood and adolescence cancer in Spain. Clin Transl Oncol. 2016;18:708-13.

12. Directive 2001/20/EC of the European Parliament and of the Council of 4 April 2001 on the approximation of the laws, regulations and administrative provisions of the member states relating to the implementation of good clinical practice in the conduct of clinical trials on medicina products for human use; 2001. https ://ec.europa.eu/health/human-use/clinical-trials/directive_en. Accessed date 25 May 2019.

13. Nordenmalm S, Tomasi P, Pallidis C. More medicines for children: impact of the EU paediatric regulation. Arch Dis Child. 2018;103:557-64.

14. Real Decreto $1090 / 2015$, de 4 de diciembre, por el que se regulan los ensayos clínicos con medicamentos, los Comités de Ética de la Investigación con medicamentos y el Registro Español de Estudios Clínicos. https://www.boe.es/buscar/doc.php?id=BOEA-2015-14082. Accessed date 25 May 2019.

15. Ramirez M, Ruano D, Moreno L, Lassaletta Á, Bautista F, Andión M, et al. First-in-child trial of celyvir (autologous mesenchymal stem cells carrying the oncolytic virus ICOVIR-5) in patients with relapsed and refractory pediatric solid tumors. J Clin Oncol. 2018;36:10543.

16. Peyrl A, Chocholous M, Azizi A, Kieran M, Nysom K, Sterba J, et al. MB-70 MEMMAT - a phase II study of metronomic and targeted anti-angiogenesis therapy for children with recurrent/progressive medulloblastoma. Neuro Oncol. 2016;18:iii113.1-113.

17. Moreno L, Moroz V, Owens C, Laidler J, Valteau-Couanet D, Gambart M, et al. Temozolomide versus irinotecan-temozolomide for children with relapsed and refractory high risk neuroblastoma (RR-HRNB): Results of the BEACON-Neuroblastoma randomized phase 2 trial-a European Innovative Therapies for Children with Cancer (ITCC)-International Society of Pediatric Oncology Europe Neuroblastoma Group (SIOPEN) trial. J Clin Oncol. 2019;37:10001.

18. Marcos-Gragera R, Galceran J, Martos C, de Munain AL, VicenteRaneda M, Navarro C, et al. Incidence and survival time trends for Spanish children and adolescents with leukaemia from 1983 to 2007. Clin Transl Oncol. 2017;19:301-16.

19. PROYECTO BEST Investigación Clínica en Medicamentos. https ://www.medicamentosinnovadores.org/sites/default/files/medin novadores/Español/InformeBEST/Informessemestrales/2017/ ResultadosBDMetrics24apublicación.pdf.

20. Primer informe sobre la investigación e innovación en cáncer en España 2018; 2018. http://observatorio.aecc.es/sites/default/files /informes/Informe-investigacion-cancer_0.pdf.

Publisher's Note Springer Nature remains neutral with regard to jurisdictional claims in published maps and institutional affiliations.

\section{Affiliations}

\section{F. Bautista ${ }^{1}$ - A. Cañete ${ }^{2}$. G. L. Ramírez-Villar ${ }^{3}$. J. M. Fernández ${ }^{2}$. J. L. Fuster ${ }^{4}$. C. Diaz de Heredia ${ }^{5}$ I. Astigarraga ${ }^{6}$. M. García-Ariza ${ }^{6} \cdot$ S. Rives ${ }^{7}$. J. L. Dapena ${ }^{7}$. C. Márquez ${ }^{3} \cdot$ A. Molinés ${ }^{8} \cdot$ M. del M. Bermúdez ${ }^{4} \cdot$ S. Gallego ${ }^{5}$. M. del M. Andrés ${ }^{2} \cdot$ J. Verdu-Amoros ${ }^{9} \cdot$ C. Hernández ${ }^{1} \cdot$ M. López $^{10}$ - A. Catalá ${ }^{7}$. Á. Lassaletta ${ }^{1}$. O. Cruz $\cdot$ M. Ramírez ${ }^{1}$.

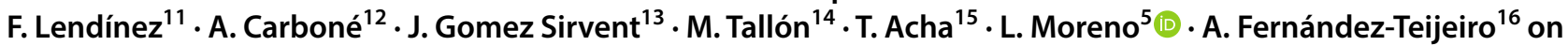 behalf of the Sociedad Española de Hematología y Oncología Pediátrica (SEHOP)}

1 Pediatric Oncology, Hematology and Stem Cell Transplant Department, Hospital Infantil Universitario Niño Jesús, Avenida Menéndez Pelayo, 65, 28009 Madrid, Spain

2 Hospital Universitario y Politécnico La Fe, Instituto de Investigación Sanitaria La Fe (IIS La Fe), Valencia, Spain

3 Hospital Universitario Virgen del Rocío, Seville, Spain

4 Hospital Universitario Virgen de la Arrixaca, Instituto Murciano de Investigación Biosanitaria (IMIB), Murcia, Spain

5 Servicio de Onco-Hematología y Transplante, Hospital Universitari Vall d'Hebrón, Passeig de la Vall d'Hebron, 119-129, 08035 Barcelona, Spain

6 Biocruces Bizkaia Health Research Institute, Hospital Universitario Cruces. Osakidetza. UPV/EHU, Barakaldo, Bizkaia, Spain

7 Hospital Sant Joan de Déu, Barcelona Institut de Recerca San Joan de Déu, Barcelona, Spain
8 Complejo Hospitalario Universitario Insular Materno-Infantil, Las Palmas de Gran Canaria, Las Palmas, Spain

9 Hospital Clínico Universitario, Valencia, Spain

10 Hospital Universitario Marqués de Valdecilla, Santander, Spain

11 Hospital Universitario Torrecárdenas, Almeria, Spain

12 Hospital Universitario Miguel Servet, Saragossa, Spain

13 Hospital Universitario Nuestra Señora de la Candelaria, Santa Cruz de Tenerife, Spain

14 Hospital Alvaro Cunqueiro, Vigo, Spain

15 Hospital Universitario Carlos Haya, Malaga, Spain

16 Hospital Universitario Virgen de la Macarena, Seville, Spain 